\title{
ENTREVISTA COM A PROFESSORA IDA ALVES SOBRE POESIA PORTUGUESA CONTEMPORÂNEA
}

Leonardo de Barros Sasaki ${ }^{1}$

Leonardo de Barros Sasaki: Qual a sua avaliação quanto ao quadro recente de produção de poesia em Portugal? É possivel aproximarmos estas poéticas - pensadas não apenas em comparação com as linhas de tensão da segunda metade do XX: os da Poesia 61, da Poesia Experimental, os do Cartucho etc. mas também em um quadro maior da tradição lírica portuguesa?

Ida Alves: Em Portugal, como já disse o Gastão Cruz, a poesia é "talvez a mais moderna das artes", expondo com exemplar atualidade e força suas inquietações e buscas. Assim, de minha perspectiva, vejo essa produção recente como extremamente interessante, expondo, ao mesmo tempo, uma vontade de deslocar o peso de toda uma tradição lírica portuguesa e uma atração inevitável por esses lugares incontornáveis da poesia ocidental. Algo como um Ulisses amarrado ao mastro do navio, com cera nos ouvidos para não ouvir as sereias...(risos). Penso também que alguns poetas portugueses que hoje têm cerca de 30, 40 anos, como Luis Quintais, Manuel de Freitas, Rui Pires Cabral, Carlos Bessa, Jorge Gomes Miranda, Pedro Mexia, Filipa Leal, Carlos Alberto Machado, José Miguel Silva, José Ricardo Nunes, Rui Lage, Antonio Carlos Cortez, Daniel Jonas (e cito sem nenhuma ordem...), entre outros nomes que poderíamos apontar, expõem com inteligência e com sensibilidade desconcertante certas questões inevitáveis de nossa contemporaneidade, como uma experiência muito mais aguda do urbano, da violência cotidiana física e existencial alimentada pela sociedade de hoje, além da vivência de mais forte deslocamento no espaço e no tempo, com o mundo virtual, com a aceleração da vida, do trabalho, em meio a formas e meios de comunicação frenéticos e fragmentários. Alto lá: não são mais nem menos poetas que os anteriores; são poetas do seu tempo, do nosso tempo, e essa “atualidade" é também uma questão que os torna interessantes. Mas esse interesse só é possível porque há os anteriores como Camões, Pessoa, Carlos de Oliveira, Jorge de Sena, Mário Cesariny, Ruy Belo, Herberto Helder e outros tantos nomes fortíssimos com os

\footnotetext{
${ }^{1}$ Mestrado em Literatura Portuguesa, na Faculdade de Filosofia, Letras e Ciên cias Humanas da Universidade
} de São Paulo (FFLCH-USP). 
quais eles inevitavelmente se confrontam ou dialogam. E é assim que o literário se movimenta.

LBS: E quanto à recep̧ão crítica, como a senhora avalia os esforços de recep̧̧ão da poesia da segunda metade do XX e desta primeira década do XXI? - não estou pensando apenas em nomes de relevo da crítica (sobre os quais obviamente seria interessante ouvir sua opinião), mas também, e, sobretudo, em termos de teses e dissertações. O que há para ser destacado e o que ainda, na sua opinião, precisa ser mais detidamente explorado? Como a senhora percebe esta construção do cânone, quero dizer, deste movimento em que alguns poetas já estão mais institucionalizados e de outros que de alguma forma são ignorados on permanecem marginais?

IA: As suas questões podem se transformar em hipóteses para muitas teses e dissertações (risos). Simplificando, porque seria impossível nesta resposta dar conta de tudo isso, avalio que a recepção de poesia tem que ser pensada em níveis diferentes e, assim, para cada nível, há um determinado estado de crítica. Em todos os níveis, porém, os modos de crítica, o seu impacto, a sua ressonância já não marcam tanto uma presença como podíamos sentir ao longo de décadas do século XX. Há agora, parece-me, uma recepção crítica muito parcial, muito lacunar em relação ao literário e especialmente em relação à poesia. Isso é uma visão geral, com todas as ressalvas, é claro. Em Portugal, a recepção crítica de poesia é ainda muito intensa e variada. Calou-se infelizmente um Eduardo Prado Coelho, mas críticos mais jovens oriundos da Universidade ou do próprio sistema literário vêm trabalhando e expondo escolhas a partir de relevantes pontos de vista. Em Portugal, em termos de crítica de poesia, admiro, porque provoca o diálogo e abre trilhas de reflexão, o trabalho dos professores Manuel Gusmão, Silvina Rodrigues Lopes, Fernando Guimarães, João Barrento, Joaquim Manuel Magalhães, Osvaldo Manuel Silvestre, Nuno Júdice, Rosa Maria Martelo, Pedro Serra, Fernando Pinto do Amaral (e a citação de nomes é ilustrativa, não exaustiva), mas me interessam ainda mais os próprios poetas em estado de crítica em relação à sua poesia e à alheia, ao sistema poético, como uma grande "sala de convívio", na bela imagem do Ruy Belo. Gosto especialmente dos poetas-críticos, desses que ocupam claramente esse lugar móvel e tenso de escritor-leitor.

Em termos da crítica acadêmica, com suas teses e dissertações, é quase matemático demonstrar que o estudo de poesia se dá com menos intensidade em relação à critica de 
narrativa. Por vezes, temos a impressão de que os alunos têm medo da poesia como se fosse uma sala fechada com permissão de entrada dada a apenas alguns eleitos... Isso infelizmente vem de um ensino, de uma cultura geral, que transformou a poesia em algo de "bom tom" mas supérfluo (estou falando muito mais em relação ao Brasil, do que a Portugal.). No entanto, mesmo assim, temos formado leitores "sem medo" e entre esses há jovens que garantirão a permanência de sua recepção e crítica. Quero ressaltar, aliás, o trabalho importante que, na área de literatura portuguesa, os professores brasileiros têm feito: divulgação, análise, formação de leitores, incentivando permanentemente o diálogo e a crítica acadêmica. Claro que há diversos níveis de sucesso nesse domínio, há trabalhos falhos, mas há também (e é isso que desejo enfatizar) uma crítica acadêmica brasileira criteriosa, competente e original da poesia portuguesa. Com essa adjetivação, quero dizer que nós temos também a habilidade de pôr em movimento leituras críticas contrastivas ou comparativas as quais, a princípio, parecem a alguns colegas portugueses "disparatadas" (risos), mas, quando o trabalho é bem feito, esses encontros inesperados são momentos críticos altamente provocativos e reveladores de aspectos que frequentemente a crítica portuguesa deixa de enxergar pelo respeito demasiado a certos limites acadêmicos sobre o "objeto" a ser examinado ou por adesão muito radical a certos princípios e valores. Estarmos aqui, do outro lado do Atlântico, a olhar o que eles produzem dá-nos certa independência de olhar, deixa-nos à vontade de ler o que desejamos, como o desejamos.

Tudo isso acarreta, em suma, um reexame crítico de hierarquias poéticas (ah, elas existem...), um confronto por vezes muito provocativo entre a tradição e o contemporâneo, entre o canônico e o lateral, entre o institucionalizado e o desconhecido, entre escalas de valores, de leituras e de recepções. No fundo, é isso que interessa e é isso que se constitui como "situação crítica" da poesia: o confronto, o espanto, a discordância e a coragem de ler diferente.

LBS: E quanto à circulação desta produção - e aípenso não somente na poesia mais recente, mas também em um quadro mais geral da produção pós 61 -, como a senhora vê a circulação desta producão no Brasil? Quais iniciativas editoriais a senhora destacaria? Quais autores são ainda supreendentemente negligenciados? 
IA: A resposta não é muito animadora, mas também não pode ser um "vale de lágrimas". Digo que a literatura portuguesa do século XX e agora XXI é, de certa maneira, uma literatura estrangeira no Brasil, como tantas outras. Claro que "circulação de produção" significa pensar em mercado, em quantidade de leitores, em objeto de consumo, em divulgação, etc. $\mathrm{E}$ esse quadro também precisa ser pensado em vários níveis, o que não podemos fazer aqui. Em linhas restritas, o que vemos: 1 - se pensarmos em termos da realidade geral brasileira, a literatura portuguesa (e mais ainda a poesia pós-60) circula muito pouco entre nós. Que nomes o leitor brasileiro, leitor comum, poderá reconhecer como português contemporâneo? José Saramago, talvez, e, no período breve de realização das famosas feiras de livro e seus modismos, algum nome convidado e badalado pela imprensa (decorrente de um trabalho eficaz de divulgação...); 2- nos Cursos de Letras, com a presença constante das disciplinas de literatura portuguesa, os alunos têm contato de maneira mais abrangente com diversos escritores, mas isso não significa um conhecimento mais intenso da produção literária portuguesa pós-60. Na verdade, na maior parte desses cursos, o contemporâneo não é examinado ou é examinado muito lateralmente, porque não dá tempo, porque não há os livros nas livrarias brasileiras, porque se desconhece mesmo o que se está fazendo agora ou se fez, em Portugal, a partir de Fernando Pessoa (isto é, a partir da divulgação maior da obra pessoana, anos 40 e 50). No Rio de Janeiro, temos uma situação mais positiva, pois, tanto na UFF, quanto na UFRJ, há uma atenção muito forte e constante ao contemporâneo e muito à poesia portuguesa (e também brasileira) pós-60. Em outros Estados, claro, aqui e ali, há outros professores em ação, em diálogo também. Mas a recepção e a circulação ainda são restritas em relação ao que poderia ser, ao que precisaria ser, se houvesse vontade cultural, política e comercial.

Temos que lembrar boas iniciativas editoriais, sim, como a "Coleção Ponte Velha", da Editora Escrituras, São Paulo, embora esse título "Ponte Velha" não me pareça muito feliz (risos). Pelo menos, há uma seleção interessante de autores, constância na edição, ótima divulgação, e são antologias que dão a ver alguma produção, com um preço acessível. Há também a jovem Oficina Raquel, do Rio de Janeiro, que produz a "Coleção Portugal, 0", com curadoria do meu colega da UFF, Luis Maffei, dedicada a poetas portugueses que começaram a publicar nos anos 90. A Editora Azougue, do Rio de Janeiro, está igualmente com um projeto sobre a poesia portuguesa que, acredito, dará bons frutos (ainda está em fase de execução). Nos últimos anos, temos tido a edição brasileira de poetas como Herberto Helder, Maria Teresa Horta, Nuno Júdice, Gastão Cruz, Luiza Neto Jorge, Fiama 
Hasse Pais Brandão e outros, mas são edições, em geral, tímidas, sem maior circulação para além dos Cursos de Letras. Quase sempre não se encontram nas prateleiras das livrarias dos shoppings, essas vitrines chamativas... Pelo menos, já começam a ser editados aqui, o que é ótimo, sem dúvida. Mas o ideal seria mesmo que os livros editados em Portugal chegassem ao Brasil com rapidez, com preços acessíveis, que houvesse uma vontade política de que toda a produção literária dos países de língua portuguesa circulasse de forma livre, sem impostos de importação que tornam o livro um absurdo para o bolso de um estudante brasileiro, por exemplo. Lembro-me que, há mais de uma década, ao querer indicar o livro O Movimento do Mundo, de Nuno Júdice, deparei-me com um único exemplar numa livraria carioca "especializada”, e o preço era um terço do salário-mínimo da época! Ora, se o livro não circula, como conhecer e ler a literatura alheia? Quantos autores são ignorados, poetas e romancistas admiráveis! E se alguns estão, pelo menos entre os leitores universitários, é devido ao trabalho intenso de leitura e divulgação que muitos de nós, professores de literatura portuguesa, fazemos. O que seria ideal não diz respeito apenas à literatura portuguesa, mas a toda produção literária e cultural: o Brasil precisa de mais livrarias, de mais incentivos à edição de obras, de mais traduções de qualidade, de mais acordos contra impostos sobre livros, de mais programas de edições conjuntas entre Brasil e outros países, de mais política cultural, de mais alfabetização séria, eficiente, de mais leitores em todos os níveis.

LBS: Falando em autores negligenciados e pensando no recente titulo organizado pela senhora: pessoalmente, quais poetas interessam mais? Por quê?

IA: O livro que Luis Maffei e eu organizamos responde plenamente à sua pergunta e eu só poderia dizer: vejam lá o sumário! (risos). Mas, falando sério e pessoalmente, os poetas que me interessam mais são todos aqueles que me apresentam um problema de leitura, uma interrogação sobre estar no mundo e na escrita. Disse anteriormente que me interessam os poetas-críticos, os poetas em estado de crítica, num mundo crítico, com um olhar crítico. Não sou fiel a um único poeta, gosto de vários, vários me interessam, muitos até mudam do estado de "desinteressante" para "interessante" a partir da leitura crítica que alguém faz, de um verso citado por outro poeta, por um poema encontrado ao acaso, e, então, eu vejo algo que desconhecia, eu redescubro, o que é uma experiência ótima. 
O que sobretudo o nosso livro quis mostrar é que a poesia portuguesa não acabou em Fernando Pessoa. Há inúmeros poetas portugueses admiráveis a serem conhecidos e "reconhecidos" entre nós. Trata-se de poetas da língua portuguesa, não importa que nascidos ou vivendo em Portugal. São também nossos poetas e não podem ficar em silêncio aqui, neste lado do Atlântico. Assim como também os nossos poetas não podem ser desconhecidos, inexistentes em Portugal e nos outros países de língua portuguesa. Toda a cultura (as culturas) de língua portuguesa nos interessa e deve nos interessar, porque nos dão um rosto, uma voz, gestos, enfim, um corpo de palavras.

Como leitora, leitora apenas, os poetas que me interessam mais são os que me "comovem" e há muitos, cada um em seu tempo e à sua maneira. Mas se você insiste em nomes, forço-me a destacar alguns do século XX, pós-Pessoa, sempre com a ressalva de que alguns outros poderiam também ser citados. As listagens, nesse tipo de assunto, são sempre injustas. Então, falo daqueles que, nos meus limites, leio e releio com mais frequência ao longo dos anos (cito em certa ordem cronológica...): Sophia de Mello Breyner Andresen, Carlos de Oliveira, Jorge de Sena, Eugénio de Andrade, António Gedeão, Mario Cesariny, António Ramos Rosa, Alexandre O'Neil, Fernando Assis Pacheco, Ruy Belo, Herberto Helder, Armando da Silva Carvalho, Maria Teresa Horta, Luísa Neto Jorge, Gastão Cruz, Fiama Hasse Pais Brandão, Nuno Júdice, Joaquim Manuel Magalhães, António Franco Alexandre, João Miguel Fernandes Jorge, Al Berto, Luis Miguel Nava, Adília Lopes, Ana Luísa Amaral, Manuel Gusmão e.... Ah, a enumeração poderia continuar... Que seja, pelo menos, um convite a descobrir as obras poéticas por trás desses nomes. 